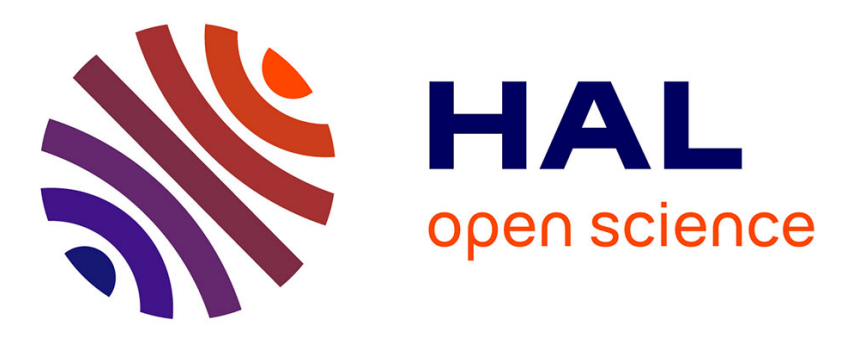

\title{
Glass forming regions, structure and properties of lanthanum barium germanate and gallate glasses
}

Florian Calzavara, Mathieu Allix, Marc Dussauze, Veronique Jubera, Marcelo Nalin, Thierry Cardinal, Evelyne Fargin

\section{- To cite this version:}

Florian Calzavara, Mathieu Allix, Marc Dussauze, Veronique Jubera, Marcelo Nalin, et al.. Glass forming regions, structure and properties of lanthanum barium germanate and gallate glasses. Journal of Non-Crystalline Solids, 2021, 571, pp.121064. 10.1016/j.jnoncrysol.2021.121064 hal-03365080

\author{
HAL Id: hal-03365080 \\ https://hal.science/hal-03365080
}

Submitted on 5 Oct 2021

HAL is a multi-disciplinary open access archive for the deposit and dissemination of scientific research documents, whether they are published or not. The documents may come from teaching and research institutions in France or abroad, or from public or private research centers.
L'archive ouverte pluridisciplinaire HAL, est destinée au dépôt et à la diffusion de documents scientifiques de niveau recherche, publiés ou non, émanant des établissements d'enseignement et de recherche français ou étrangers, des laboratoires publics ou privés. 


\title{
Glass forming regions, structure and properties of lanthanum barium germanate and gallate glasses
}

\author{
Florian Calzavara $^{\mathrm{a}^{*}}$, Mathieu Allix $^{\mathrm{b}}$, Marc Dussauze ${ }^{\mathrm{c}}$, Véronique Jubera $^{\mathrm{a}}$, Marcelo Nalin ${ }^{\mathrm{d}}$, \\ Thierry Cardinal $^{\mathrm{a}}$, Evelyne Fargin ${ }^{\mathrm{a}}$
}

${ }^{a}$ Institut de Chimie de la Matière Condensée de Bordeaux, Université de Bordeaux, 87 Avenue du Dr Schweitzer, Pessac F-33608, France

${ }^{\mathrm{b}}$ Conditions Extrêmes et Matériaux : Haute Température et Irradiation, UPR3079, Université d'Orléans, 1 Avenue de la Recherche Scientifique, 45100 Orléans, France

${ }^{\mathrm{c}}$ Institut des Sciences Moléculaires, UMR 5255, Université de Bordeaux, 351 cours de la Libération, Talence Cedex 33405, France

d Institute of Chemistry - São Paulo State University-UNESP, Rua Prof. Francisco Degni, 55, CEP 14800060, Araraquara -SP, Brazil

*Corresponding author: florian.calzavara@icmcb.cnrs.fr

\section{$\underline{\text { Abstract }}$}

Glass forming regions in the system $\mathrm{GaO}_{3 / 2}-\mathrm{GeO}_{2}-\mathrm{LaO}_{3 / 2}-\mathrm{BaO}$ have been explored using aerodynamic levitation coupled to laser heating synthesis technique. Structure property relationships have been established between the thermal and optical properties of the resulting glass thanks to Raman and Infrared vibrational spectroscopies. The germano-gallate glass networks are mainly made of three-dimensional interconnected corner shared $\mathrm{GeO}_{4}$ and $\mathrm{GaO}_{4}$ tetrahedra forming $\mathrm{Ge}-\mathrm{O}-\mathrm{Ge}$ and $\mathrm{Ga}-\mathrm{O}^{-}-\mathrm{Ge}$ bridges in which gallium tetrahedral $\mathrm{GaO}_{4}$ units are charged-compensated by barium and lanthanum cations. In $\mathrm{GeO}_{2}$-rich compositions, the excess of positive charges produces mainly non-bridging oxygens on germanate moieties, leading to a depolymerization of the glass network. In the case of gallium rich compositions, the infrared cut-off is redshifted as compared to the germanate glasses, in accordance with the disappearance of germanium associated entities such as germanium and gallium bridges or germanium sites with non-bridging oxygen both vibrating at higher wavenumber.

Keywords: heavy-metal oxide glasses, germano-gallate glasses, glass structure, vibrational Infrared and Raman spectroscopies, aerodynamic levitation coupled to laser heating. 


\section{Introduction}

Novel mid-infrared (MIR) transparent materials are attracting attention for the development of all on-chip photonic devices either as active or passive components [1]. Being transparent in the fingerprint window of various molecular species, they offer the possibility to easily detect traces of environmental gases and toxic vapors, such finding a variety of applications in health [2], environment, atmospheric, telecommunication and defense or security. Vitreous systems based on heavy metal oxide (HMO) are particularly of interest since they can be readily shaped with reasonable costs, providing a mechanically robust and chemically durable alternative to fluoride and chalcogenide glasses, even though their transparent window extension towards the mid-IR remains less extended. Compared with common oxide glass systems such as (alumino-)silicates, borates or phosphates, HMO glasses possess a large transmission window ranging from the ultraviolet domain to mid-infrared (transmission cut-off up to $\sim 8 \mu \mathrm{m}$ ) [3]. They also exhibit a relatively high third order polarizability which make HMO glasses suitable for nonlinear applications [4]. In the past, bismuthate-, lead, scandium-, thallium- germanate-based [5] or gallate-based [3], [4], [6]-[20] glasses were particularly investigated. However, the toxicity of some constituent may limit their use. Barium germano-gallate (BGG) glasses have been alternatively developed following the pioneer work of Higby [21], emphasizing their usefulness for optical components such as low-loss optical fibers [21] or bulk optics [22]-[25]. The introduction of either low field cations (i.e. alkaline-earth $\mathrm{MO}$ or alkaline $\mathrm{M}_{2} \mathrm{O}$ ) or by substituting barium oxide into the modified BGG low phonon glass systems have been recently investigated [24], [25]. The glass network is reported to be formed of 3D tetrahedral sites of oxygenated germanium and gallium in which the alkaline earth and alkali compensate the gallium tetrahedral negative charge. We have previously reported that such compositions tend to lead to strong surface crystallization [26], [27], making difficult the development of waveguiding optical fibers for instance using preform based technologies [24] [25].

Alternatively, the introduction of high field rare-earth (RE) components in germano-gallate glasses has been little explored even if fiber drawing has been reported [28]-[33]. Introduction of rare-earth ions for laser applications are of importance and requires to investigate the effect of rare-earth introduction on the glass structure and properties. Following our previous works, here we explore the multicomponent glass forming diagram $\mathrm{GaO}_{3 / 2}-\mathrm{GeO}_{2}-\mathrm{BaO}-\mathrm{LaO}_{3 / 2}$ while varying the barium oxide content from zero up to twenty cationic molar percent. Main relationships between physical, thermal and structural properties will be discussed. The investigation of the vitreous domain was explored using aerodynamic levitation coupled to laser heating (ADL) to access high melting temperatures and fast quenching rates with a contactless approach to avoid heterogeneous crystallisation. The melts were reproduced in most cases using classical melt-quenching techniques in order to obtain centimeter size samples. Nonetheless, glasses with no germanium oxide could not be obtained using traditional melt quenching technique. Vibrational spectroscopies have been investigated in order to establish composition/structure/properties relationships.

\section{$\underline{\text { Experimental procedure }}$}

Glasses were elaborated using high purity powders $\mathrm{Ga}_{2} \mathrm{O}_{3}$ (Fox Chemicals, $\leq 99.999 \%$ ), $\mathrm{GeO}_{2}$ (Fox Chemicals, $\leq 99.999 \%$ ), $\mathrm{La}_{2} \mathrm{O}_{3}$ (Stream Chemicals, $\left.\leq 99.99 \%\right)$ and $\mathrm{BaCO}_{3}$ (Fox Chemicals, $\left.\leq 99.99 \%\right)$. The 
mixtures were then grinded and pressed into pellets before being placed in the ADL setup. Melting temperatures between $\sim 1450{ }^{\circ} \mathrm{C}$ and $\sim 1700{ }^{\circ} \mathrm{C}$ were attained using two $\mathrm{CO}_{2}$ lasers with an operating wavelength of $\lambda=10.6 \mu \mathrm{m}$. An argon flux was used to levitate the melted sphere during the whole synthesis process. The spherical melt was homogenized during a few seconds. Samples of $3 \mathrm{~mm}$ diameter were successively quenched down to room temperature by shutting down the laser power. Spherical, transparent and colorless glasses were been obtained as shown in Figure 1e. No further thermal annealing was performed. Finally, the samples were cut and polished on both parallel faces for further characterizations. The compositions have been normalized as follow: $\mathrm{x} \mathrm{GaO}_{3 / 2}+\mathrm{y} \mathrm{GeO}+\mathrm{z} \mathrm{LaO}_{3 / 2}=100$ cationic molar percentage (cationic mol \%) where $\mathrm{x}, \mathrm{y}$ and $\mathrm{z}$ correspond, respectively, to the gallium, germanium and lanthanum oxides cationic molar percentages.

\section{Physical and thermal characterizations.}

Thermal properties including the onset of glass transition temperature $\left(T_{g}\right)$ and the onset of crystallization $\left(T_{x}\right)$ were measured on a Netzsch DSC Pegasus 404 F3 apparatus in a platinum pan using glass chunks of about 10 $-20 \mathrm{mg}$. A heating rate of $10{ }^{\circ} \mathrm{C} \cdot \mathrm{min}^{-1}$ has been used. The onset of $T_{g}$ and $T_{x}$ were determined from the DSC trace from the tangents crossing The error has be estimated to be equal to $\pm 4{ }^{\circ} \mathrm{C}$. The density $\rho$ was obtained from the average of five measurements per sample using Archimedes' method by immerging a glass chunk in diethyl phthalate at room temperature on a Precisa XT 220A weighing scale. The estimated errors were estimated around $\pm 0.01 \mathrm{~g} . \mathrm{cm}^{-3}$.

Optical properties have been investigated by transmission measurements. The extinction coefficient $\alpha$ has been deduced from the transmission spectra according to the relation $\alpha=-\frac{\ln \left(I / I_{0}\right)}{x}$, where $x$ is the sample's thickness and $\mathrm{I} / \mathrm{I}_{0}$ the transmission percentage. In this case, we assume that the extinction coefficient can be considered as the absorption coefficient due to negligible scattering in the samples The infrared transmission spectra were recorded on a spectrometer Brüker Equinox 55 from $4000 \mathrm{~cm}^{-1}$ to $1000 \mathrm{~cm}^{-1}$ with a spectral resolution of $4 \mathrm{~cm}^{-1}$. The spectra have been recorded from an average of 128 scans. The ultraviolet- visible transmission spectra were recorded on a Cary5000 (Varian) from $200 \mathrm{~nm}$ to $2500 \mathrm{~nm}$ with a spectral resolution of $1 \mathrm{~nm}$.

Structural characterizations by vibrational spectroscopies.

Unpolarized Raman spectra were recorded with a confocal micro-Raman spectrometer LabRAM HR Evolution (Horiba Jobin Yvon) equipped with a Synapse CCD detector cooled down to $-70{ }^{\circ} \mathrm{C}$ using a 532$\mathrm{nm}$ radiation from a diode pumped solid state laser (output power $=20 \mathrm{~mW}$ ). The incident laser beam was focused onto the sample through a microscope with a 50x objective (NA $=0.50$, Olympus). Scattered light was dispersed by 1200 grooves. $\mathrm{mm}^{-1}$ grating system. Raman spectra have been corrected by the Bose-Einstein factor. They have then been normalized between $400 \mathrm{~cm}^{-1}$ and $1000 \mathrm{~cm}^{-1}$ with respect to the maximum intensity peak located in the low frequency range defined as $400-600 \mathrm{~cm}^{-1}$.

Reflectance infrared spectra have been recorded with an incident angle of $11^{\circ}$ from 200 to $1500 \mathrm{~cm}^{-1}$ with a spectral resolution of $4 \mathrm{~cm}^{-1}$ using a Fourier Transform Spectrometer Vertex $70 \mathrm{~V}$. A mid-infrared source has 
been used (globar type). All measurements were performed in vacuum. The spectra have been averaged from three measurements of 200 scans each. Kramers-Kronig transforms have been performed in order to extract the extinction coefficient $\mathrm{k}$ from the imaginary part of the refractive index $\underline{n}$ according to the relation $\underline{n}=\mathrm{n}_{0}+$ $\mathrm{i} \mathrm{k}$ with $\mathrm{n}_{0}$ the linear refractive index.

\section{$\underline{\text { Results }}$}

The obtained glass formation domains explored using aerodynamic levitation melting process are reported in Figure 1. We focused the investigation on the main network former domain corresponding to germanium and gallium oxides-rich compositions as depicted in Figure 1. Under our synthesis conditions, we report in Figure 1a-d the glass forming regions in the multicomponent system $(1-\alpha)\left(\mathrm{x} \mathrm{GaO}_{3 / 2}-\mathrm{y} \mathrm{GeO}_{2}-\mathrm{z} \mathrm{LaO}_{3 / 2}\right)-\alpha \mathrm{BaO}$ for four fixed values of the barium oxide content $\alpha$ ranging from zero up to twenty cationic molar percent ( $\alpha$ $=0,10,16,20$ ). The vitreous domain for the barium-free diagram (Figure 1a) corresponds to germanate-type glasses in which the germanium oxide content ranges from about $~ 30 \%$ up to $\sim 65 \% \mathrm{GeO}_{2}$ cationic molar percent. The reported diagram is in relatively good accordance with the work already described by several authors [28], [29] and by Hwa et al.[29], [34]. When $10 \%$ of barium oxide content is added (Figure 1b), the vitreous domain is extended to the richest germanium oxide-containing glasses and in the region with the lowest lanthanum oxide amount. Gallate-rich and germanium-free glasses can be also synthesized. The region corresponding to gallium concentrations up to $\sim 75 \%$ of $\mathrm{GaO}_{3 / 2}$ content was not explored. With $16 \%$ of barium oxide content in the $\mathrm{Ga}_{2} \mathrm{O}_{3}-\mathrm{GeO}_{2}-\mathrm{La}_{2} \mathrm{O}_{3}$ system, a similar glass forming region (Figure 1c) as compared with the region with 10 cationic percent of barium oxide is obtained. For 20 cationic percent of barium oxide introduced, a shrink of the vitreous domain occurs with in particular no glass formation in the gallium-rich and the lanthanum-rich region.

The relationships between the glass compositions, thermal, optical and structural properties was further studied according to two specific series of glasses labelled (i) "BaO" (marked with $\bullet$ in Figure 1) and (ii) " $\mathrm{GeO}_{2}$ " (marked with $>$ in Figure 1). The first series has been designed to investigate the influence of the barium oxide content while keeping fixed the ratios $\mathrm{GaO}_{3 / 2}: \mathrm{GeO}_{2}(=1: 2)$ and $\mathrm{LaO}_{3 / 2}: \mathrm{GaO}_{3 / 2}(=4: 5)$. The first ratio has been fixed to maintain the proportion of network glass former and the second ratio assumes that equivalent amount of lanthanum and gallium ensure the compensation of the $\left(\mathrm{GaO}_{4}\right)^{-}$units. The second series focus on the influence of the germanium oxide content while preserving the ratios $\mathrm{LaO}_{3 / 2}: \mathrm{GaO}_{3 / 2}:(=4: 1)$ for a fixed barium oxide content equals to 10 cationic molar percent. We summarized the investigated glass compositions in Table 1. Beside the composition corresponding to Ge-0, all compositions corresponding to the glassy domain have been reproduced for the study using classical melt quench techniques in platinum crucible. 


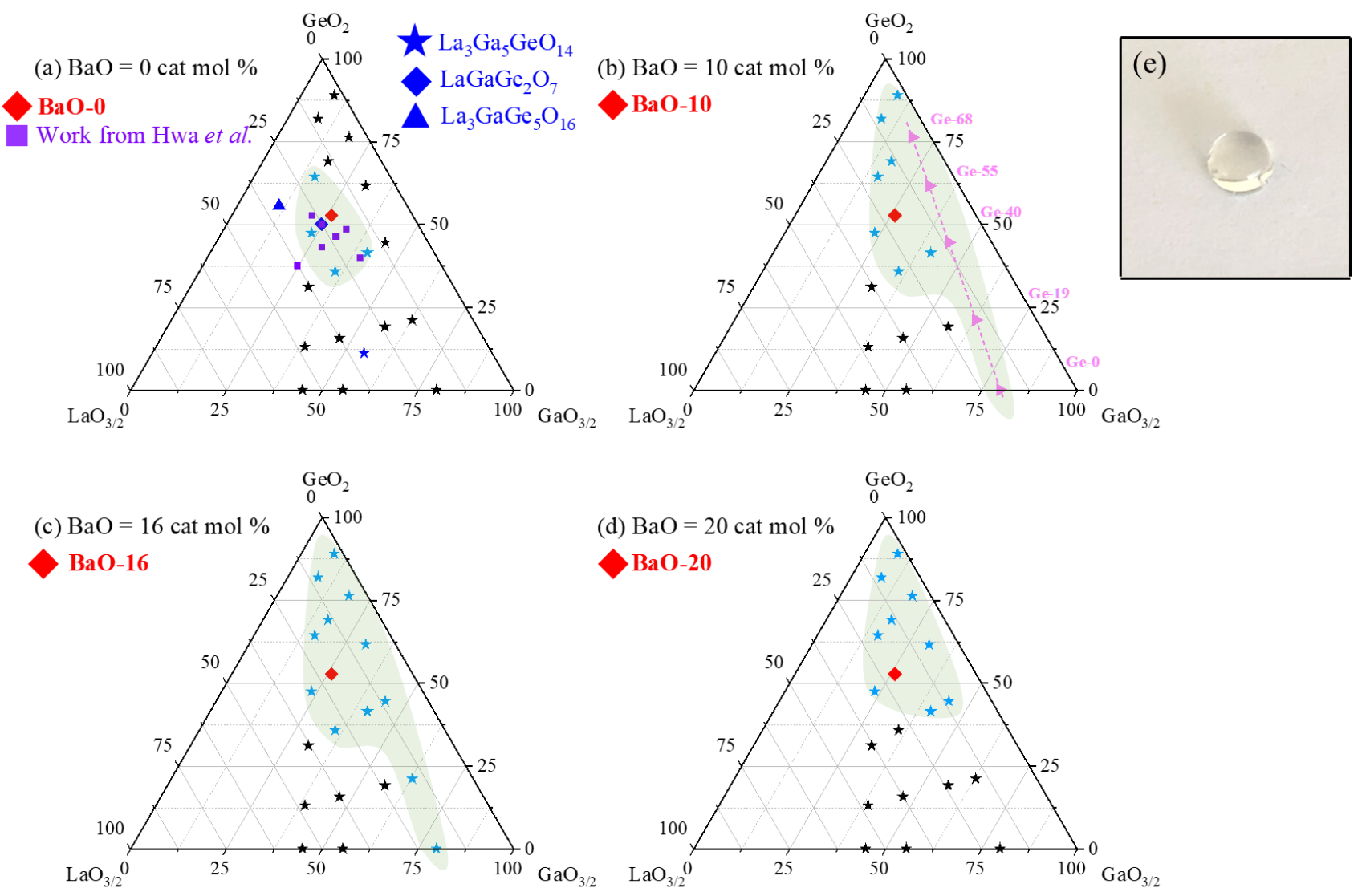

Figure 1: Glass forming multicomponent vitreous formation diagrams in the pseudo-ternary system $(1-\alpha)(\mathrm{x}$ $\mathrm{GaO}_{3 / 2}-\mathrm{y} \mathrm{GeO}_{2}-\mathrm{z} \mathrm{LaO}_{3 / 2}$ ) $-\alpha \mathrm{BaO}$ varying the barium oxide content $\alpha$ as follows: (a) 0 (b) 10 (c) 16 (d) 20 cationic molar percent (abbreviated cat mol \%). The obtained vitreous formation domains are highlighted with

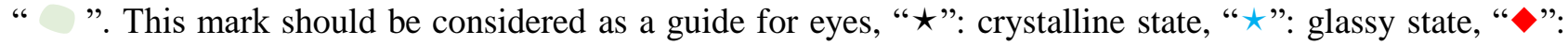
investigated samples in the $\mathrm{BaO}$ series, “ $>$ ": investigated samples in the $\mathrm{GeO}_{2}$ series, “凶$\star$ ”: main crystalline phases, "\# ": work reported by Hwa et al. [30]. Picture of one obtained glass samples is shown in (e).

\begin{tabular}{|c|c|c|c|c|c|c|c|c|c|c|c|}
\hline & \multirow[b]{3}{*}{ Sample } & & & & & & & & & & \\
\hline & & \multicolumn{4}{|c|}{ Compositions (mol \%) } & \multicolumn{4}{|c|}{ Compositions (cat mol \%) } & \multicolumn{2}{|c|}{ Cationic molar ratios (cat mol \%) } \\
\hline & & $\mathrm{Ga}_{2} \mathrm{O}_{3}$ & $\mathrm{GeO}_{2}$ & $\mathbf{L a}_{2} \mathrm{O}_{3}$ & $\mathrm{BaO}$ & $\mathrm{GaO}_{3 / 2}$ & $\mathrm{GeO}_{2}$ & $\mathrm{LaO}_{3 / 2}$ & $\mathrm{BaO}$ & $\mathrm{R}=\mathrm{GaO}_{3 / 2}: \mathrm{GeO}_{2}$ & $\mathrm{Q}=\left(2 \mathrm{BaO}+3 \mathrm{LaO}_{3 / 2}\right): \mathrm{GaO}_{3 / 2}$ \\
\hline \multirow{4}{*}{$\begin{array}{c}\mathrm{BaO} \\
\text { glass series }\end{array}$} & BaO-0 & 17.24 & 68.97 & 13.79 & 0.00 & 26.32 & 52.63 & 21.05 & 0.00 & 0.5 & 2.40 \\
\hline & BaO-10 & 15.00 & 60.00 & 12.00 & 13.00 & 23.62 & 47.24 & 18.90 & 10.24 & 0.5 & 3.27 \\
\hline & BaO-16 & 13.71 & 54.84 & 10.97 & 20.48 & 21.99 & 43.98 & 17.60 & 16.43 & 0.5 & 3.89 \\
\hline & BaO-20 & 12.99 & 51.95 & 10.38 & 24.68 & 21.06 & 42.11 & 16.83 & 20.00 & 0.5 & 4.30 \\
\hline \multirow{5}{*}{$\begin{array}{c}\mathrm{GeO}_{2} \\
\text { glass series }\end{array}$} & Ge-0 & 65.14 & 0.00 & 16.28 & 18.58 & 71.81 & 0.00 & 17.95 & 10.24 & - & 1.04 \\
\hline & Ge-19 & 43.90 & 29.27 & 10.97 & 15.86 & 56.69 & 18.90 & 14.17 & 10.24 & 3 & 1.11 \\
\hline & Ge-40 & 26.57 & 53.14 & 6.65 & 13.64 & 39.89 & 39.89 & 9.98 & 10.24 & 1 & 1.26 \\
\hline & Ge-55 & 16.69 & 66.76 & 4.17 & 12.38 & 27.62 & 55.24 & 6.90 & 10.24 & 0.5 & 1.49 \\
\hline & Ge-68 & 9.57 & 76.57 & 2.39 & 11.47 & 17.10 & 68.39 & 4.27 & 10.24 & 0.25 & 1.95 \\
\hline
\end{tabular}


Table 1: Selected glass series and their theoretical compositions in the glass forming pseudo-ternary diagrams $\mathrm{GaO}_{3 / 2}-\mathrm{GeO}_{2}-\mathrm{LaO}_{3 / 2}-\mathrm{BaO}$ (molar percentage and cationic molar percentage) - Main theoretical cationic ratios has been defined as $\mathrm{R}=\mathrm{GaO}_{3 / 2}: \mathrm{GeO}_{2}$ and $\mathrm{Q}=\left(2 \mathrm{BaO}+3 \mathrm{LaO}_{3 / 2}\right): \mathrm{GaO}_{3 / 2}$.

Table 2: Thermal properties ( $T_{g}$ : onset of the glass transition temperature; $T_{x}$ : onset of the crystallization temperature and $\Delta T$ : thermal stability $\left(T_{x}-T_{g}\right)$ ) and physical properties ( $\rho$ : bulk density) of the investigated glass samples.

\begin{tabular}{|c|c|c|c|c|c|}
\hline & Sample & $\begin{array}{c}T_{g} \\
\left( \pm 4{ }^{\circ} \mathrm{C}\right)\end{array}$ & $\begin{array}{c}T_{x} \\
\left( \pm 4^{\circ} \mathrm{C}\right)\end{array}$ & $\begin{array}{c}\Delta T \\
\left( \pm 8^{\circ} \mathbf{C}\right)\end{array}$ & $\left( \pm 0.01{\mathrm{~g} . \mathrm{cm}^{-3}}^{-3}\right)$ \\
\hline \multirow{4}{*}{$\begin{array}{c}\mathrm{BaO} \text { glass } \\
\text { series }\end{array}$} & $\mathrm{BaO}-0$ & 728 & 837 & 109 & 5.20 \\
\hline & $\mathrm{BaO}-10$ & 718 & 843 & 125 & 5.14 \\
\hline & $\mathrm{BaO}-16$ & 714 & 863 & 149 & 5.10 \\
\hline & $\mathrm{BaO}-20$ & 713 & 841 & 128 & 4.91 \\
\hline \multirow{5}{*}{$\begin{array}{c}\mathrm{GeO}_{2} \\
\text { glass series }\end{array}$} & $\mathrm{Ge}-0$ & 748 & 825 & 77 & 5.39 \\
\hline & Ge-19 & 718 & 826 & 108 & 5.18 \\
\hline & $\mathrm{Ge}-40$ & 713 & 857 & 144 & 4.97 \\
\hline & Ge-55 & 661 & 810 & 149 & 4.67 \\
\hline & Ge-68 & 639 & 728 & 89 & 4.43 \\
\hline
\end{tabular}
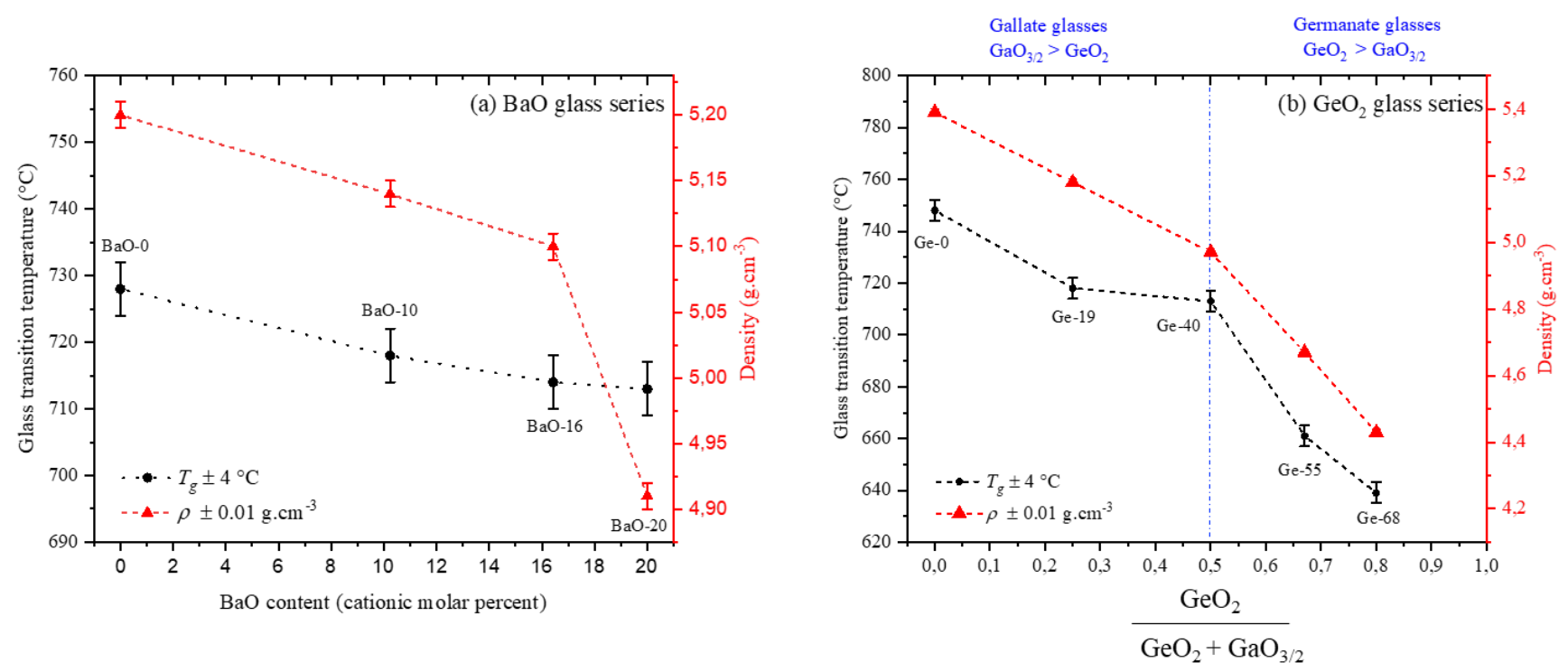

Figure 2: Glass transition temperatures $T_{g}$ and bulk densities versus their respective (a) barium oxide $\mathrm{BaO}$ and (b) the $\mathrm{GeO}_{2} /\left(\mathrm{GeO}_{2}+\mathrm{GaO}_{3 / 2}\right)$ ratio. The dashed line are guides for eyes. The blue dashed line denotes the separation between germanate $\left(\mathrm{GaO}_{3 / 2}<\mathrm{GeO}_{2}\right)$ and gallate $\left(\mathrm{GaO}_{3 / 2}>\mathrm{GeO}_{2}\right)$ compositions.

Physical and thermal properties.

The glass transition temperature, the onset temperature of the crystallization and the "thermal stability" toward crystallization $\Delta T\left(=T_{x}-T_{g}\right)$ and the glass density for both glass series are reported in Table 2 .

Regarding the $\mathrm{BaO}$ glass series, as depicted in Figure 2a, both the glass transition temperature and the density evolve nonlinearly versus the barium oxide content. The introduction of $\mathrm{BaO}$ is first characterized by 
a linear decrease of the glass density from $5.20 \pm 0.01 \mathrm{~g} . \mathrm{cm}^{-3}$ down to $5.10 \pm 0.01 \mathrm{~g} . \mathrm{cm}^{-3}$ between $\mathrm{BaO}-0$ and $\mathrm{BaO}-16$ samples respectively and then drop for cationic mol\% of $\mathrm{BaO}$ above 16 . The glass transition temperatures $T_{g}$ decrease continuously from $728{ }^{\circ} \mathrm{C}$ for BaO-0 down to $714{ }^{\circ} \mathrm{C}$ for BaO-16 samples. Then, glass transition $T_{g}$ appears fairly constant for $\mathrm{BaO}-16$ and $\mathrm{BaO}-20$. The decrease of the glass transition temperature can be related to the lowest $\mathrm{Ba}-\mathrm{O}$ bond dissociation energy $\left(\mathrm{D}^{0}{ }_{298 \mathrm{~K}}=562 \mathrm{~kJ} / \mathrm{mol}[35]\right)$ as compared to $\mathrm{La}-\mathrm{O}\left(\mathrm{D}^{0}{ }_{298 \mathrm{~K}}=798 \mathrm{~kJ} / \mathrm{mol}[35]\right)$ and also to the fact that the proportion of germano-gallate glass skeleton decreases when the barium oxide content increases. However, the nonlinear evolution of the glass transition temperature and the density versus the barium oxide concentration indicates a structural change between the $\mathrm{BaO}-0$ to the $\mathrm{BaO}-16$ composition which becomes important above 16 cationic molar $\%$ of $\mathrm{BaO}$.

Regarding the $\mathrm{GeO}_{2}$ glass series, the evolution of the physical properties of the $\mathrm{GeO}_{2}$ series seems to follow two different behaviors which are related to the proportion of the main glass former constituent, i.e. germanate $\left(\mathrm{GaO}_{3: 2} / \mathrm{GeO}_{2}<1\right)$ or gallate $\left(\mathrm{GaO}_{3: 2} / \mathrm{GeO}_{2}>1\right)$. The two domains are separated by the blue dashed line in Figure 2b. The strongest rate corresponds to the germanate network part (Ge-68 to Ge-40) and the slowest for gallate glasses (Ge-40 to Ge-0). Indeed, an important density change from $4.43 \pm 0.01{\mathrm{~g} . \mathrm{cm}^{-3}}^{-3}$ up to $4.97 \mathrm{~g} . \mathrm{cm}^{-3}$ occurs between the germanate samples labelled Ge-68, Ge-55 and Ge-40. A strong change of the glass transition temperatures from $639^{\circ} \mathrm{C}$ up to $713{ }^{\circ} \mathrm{C}\left(+74{ }^{\circ} \mathrm{C}\right)$ can be also observed for the samples Ge-68 and Ge-40 respectively. In this series, a threshold appears around $\mathrm{GaO}_{3: 2}: \mathrm{GeO}_{2} \sim 1$ which corresponds to the Ge-40 sample. In the gallate glass domain, the glass transition temperatures evolve slightly from $713{ }^{\circ} \mathrm{C}$ up to $748{ }^{\circ} \mathrm{C}\left(+35^{\circ} \mathrm{C}\right)$ for the sample Ge-40 and Ge-0 respectively. One has to remember that in this last composition range, the amount of $\mathrm{GaO}_{3 / 2}$ increases faster only from $39.89 \mathrm{cat}$ mol \% up to $71.81 \mathrm{cat} \mathrm{mol} \%$. The $T_{g}$ evolution is most probably mainly related to the change of the network glass former even if the lanthanum oxide content increases also in this composition range. Regarding the density, the evolution versus the proportion of germanium is less pronounced than for the glass transition temperature. Nevertheless, a decrease of the slope of the density evolution versus the germanium oxide proportion in the gallate glass section when $\mathrm{GeO}_{2}<\mathrm{GaO}_{3 / 2}$ can be observed in Figure 2b.

\section{Optical Transmission}

The transmission spectra for the $\mathrm{BaO}$ and $\mathrm{GeO}_{2}$ glass series shown in Figure 3 display a large transmission window ranging from ultraviolet $\lambda_{U V}(\sim 300 \mathrm{~nm})$ up to mid-infrared $\lambda_{I R}(\sim 5500 \mathrm{~nm})$. A large asymmetric broad band ranging from $\sim 2700 \mathrm{~nm}$ up to $\sim 3600 \mathrm{~nm}$ can be assigned to the stretching vibrations of hydroxyl ions which is related to the absence of specific purification steps during the glass synthesis. The absorption band around $\sim 4200 \mathrm{~nm}$ could be assigned to the overtone of a stretching motion such as $\mathrm{Ge}-\mathrm{OH}$. Regarding the infrared cut-off, notable spectral variations can be seen in Figure $3 \mathrm{~b}$ depending on the amount of barium oxide content. The cut-off at the lowest wavelength seems to be related to a strong absorption band located around $\sim 6200 \mathrm{~nm}$ for the BaO-20 sample. Several structural aspects affecting the infrared vibrations and their overtone have to be taken into account for assigning this spectral change, making a clear correlation difficult. 


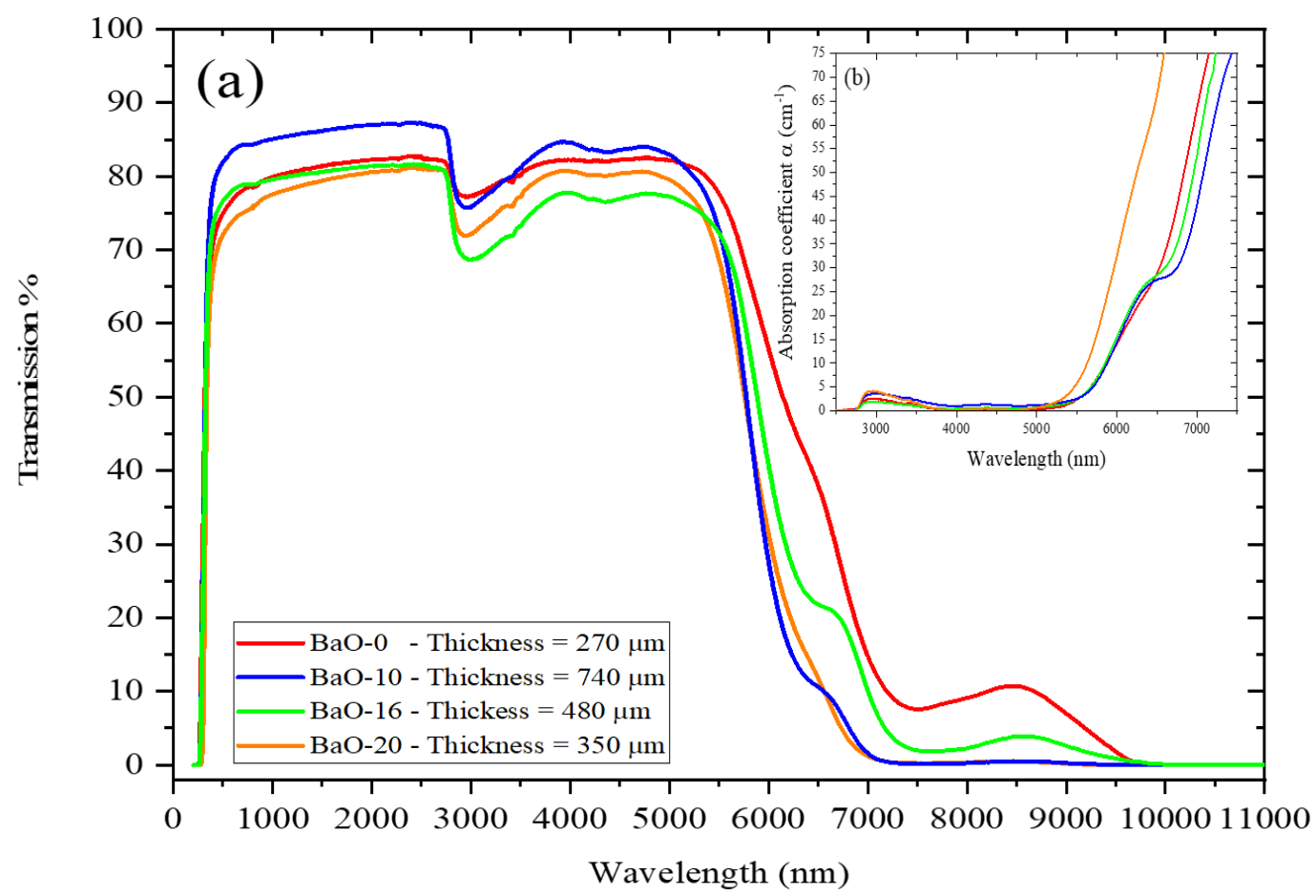

Figure 3: (a) Transmission spectra of the $\mathrm{BaO}$ glass series and their respective thickness - Absorption coefficient calculated in (b) the near-and mid-infrared range for the $\mathrm{BaO}-0, \mathrm{BaO}-10, \mathrm{BaO}-16$ and $\mathrm{BaO}-20$ glass samples.

In the $\mathrm{GeO}_{2}$ glass series, the insertion of gallium oxide in the germanate networks contributes to extend the infrared transparency from $\sim 5500 \mathrm{~nm}$ to $\sim 6500 \mathrm{~nm}$ as depicted in Figure 4a. The infrared cut-off is mainly related to the presence of an absorption band around $6200 \mathrm{~nm}$ and $7200 \mathrm{~nm}$ which is well seen on the richest $\mathrm{GeO}_{2}$ containing sample (Ge-68) sample (Figure $4 \mathrm{~b}$ ). This latter sample was polished down to a thin thickness lower than $200 \mu \mathrm{m}$ allowing to visualize the band maximum position by transmission measurement. One can also notice that the absorption band located between $2700 \mathrm{~nm}$ and $3600 \mathrm{~nm}$ previously assigned to hydroxyl ions disappear for the pure gallate sample Ge- 0 . This suggests that the hydroxyl group presence is related to the introduction of germanium oxide in the glass composition. 

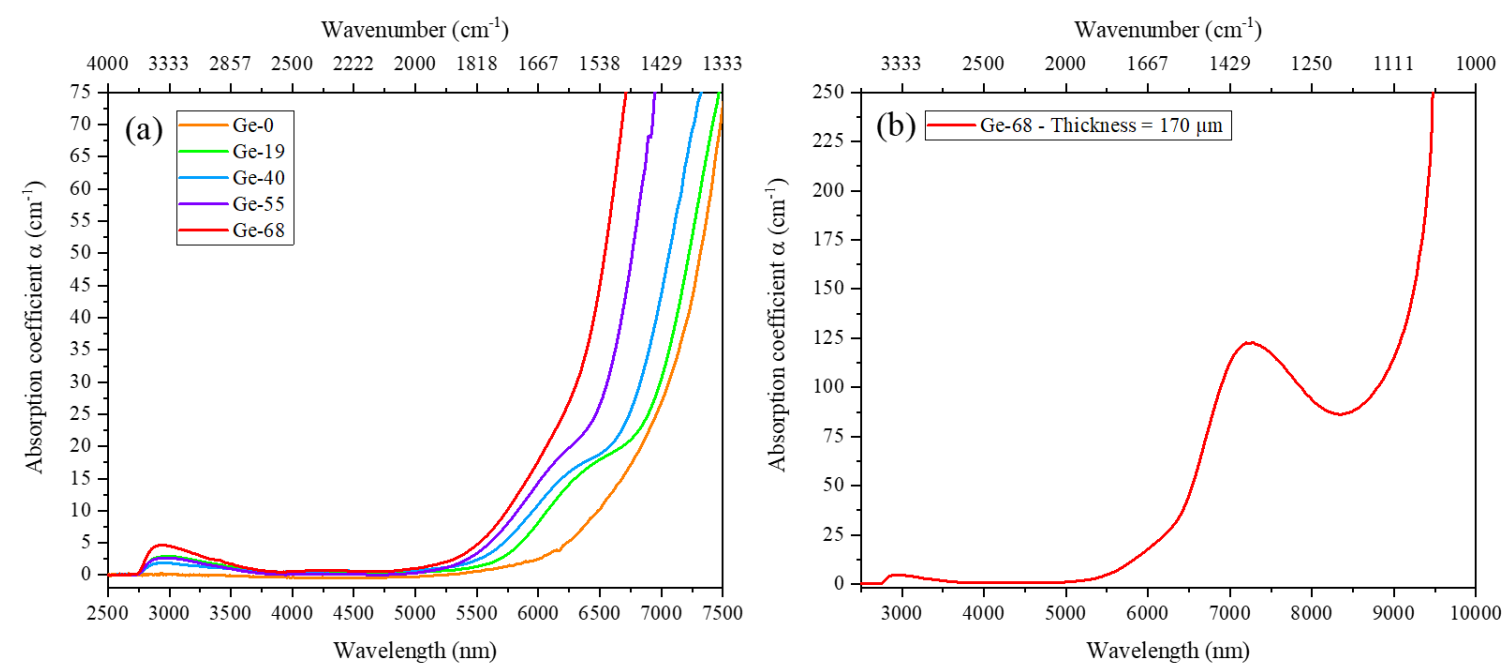

Figure 4: (a) Absorption coefficient for the $\mathrm{GeO}_{2}$ series - (b) Absorption coefficient for a thin polished glass sample Ge-68 (thickness $=170 \mu \mathrm{m}$ )

\section{Vibrational spectroscopy analysis}

Unpolarized Raman and Fourier transformed infrared spectra from $\mathrm{BaO}$ and $\mathrm{GeO}_{2}$ investigated series are respectively presented in Figure 5 and in Figure 6. The spectra have been normalized to the broad band located around $500 \mathrm{~cm}^{-1}$. Regarding the $\mathrm{BaO}-16$ and Ge-19 compositions, the small size of the sample obtained did not allow recording FTIR spectra. Those vibrational spectra exhibit two main contributions in low and high frequency regions respectively located between $400-630 \mathrm{~cm}^{-1}$ and $630-1000 \mathrm{~cm}^{-1}$. The lowermost frequency region is mainly characteristic to a combination of stretching $v\left(\mathrm{~T}^{[4]}-\mathrm{O}-\mathrm{T}^{[4]}\right)$ and $\delta\left(\mathrm{T}^{[4]}-\mathrm{O}-\mathrm{T}^{[4]}\right)$ bending modes of an oxygen surrounded by two tetrahedral units ( $\mathrm{T}=$ gallium, germanium) linked by their corners [36]. The uppermost domain are reported to contain more localized stretching features of germanium and gallium sites involved respectively in $Q_{n=1,2,3,4}$ germanate units [37] and $Q_{4}$ gallate units [29], [34] [36]. As previously reported, Raman active vibrations in this frequency domains involve germanium tetrahedra with non-bridging oxygens [36], [38], but stretching vibrations from $\mathrm{T}^{[4]}-\mathrm{O}-\mathrm{T}^{[4]}$ skeleton in a mixed interconnected $\mathrm{Ga}^{[4]}-\mathrm{O}^{-}-\mathrm{Ge}^{[4]}$ bridges are also expected [36]. While these stretching vibrations are inactive in Raman in $\mathrm{Ge}-\mathrm{O}$ - Ge bridges, the presence of an additional negative electronic contribution on the oxygen along the mixed interconnected $\mathrm{Ga}^{[4]}-\mathrm{O}^{-}-\mathrm{Ge}^{[4]}$ bridges make those vibrational modes both Raman and IR active [36]. The negative charge on oxygen ions is, in this case, balanced by the barium or lanthanum cation.

In the $\mathrm{BaO}$ series, regarding the low frequency band, two main spectral variations can be highlighted upon the insertion of barium oxide: (i) a shrink of the Raman band between 400 and $600 \mathrm{~cm}^{-1}$ and (ii) a shift of the maximum intensity from $\sim 530 \mathrm{~cm}^{-1}$ down to $\sim 510 \mathrm{~cm}^{-1}$. The Raman peak around $\sim 530 \mathrm{~cm}^{-1}$ has already been reported by several authors [26], [36] and assigned to coupled bending and stretching vibrational modes of Ga $-\mathrm{O}^{-}-\mathrm{Ge}$ bridges in which positive cations act as charge compensator and in which $(\mathrm{Ga}, \mathrm{Ge})$ tetrahedra are connected with their corners. The shift to lower frequency could indicate a depolymerization of the glass skeleton upon the increase of the barium oxide content. In the high frequency region above $650 \mathrm{~cm}^{-1}$, in order 
to illustrate the evolution, the Raman and infrared spectra have been deconvoluted in the high frequency region for the $\mathrm{BaO}$ series using five vibration contributions located at $\sim 690 \mathrm{~cm}^{-1}$ (labelled "1"), $755 \mathrm{~cm}^{-1}$ (labelled “2”), $785 \mathrm{~cm}^{-1}$ (labelled “3”), $825 \mathrm{~cm}^{-1}$ (labelled "4") and $890 \mathrm{~cm}^{-1}$ (labelled "5"). Gaussian mathematical functions have been selected for the simulation. For the simulation of the various compositions, the Raman and infrared spectra have been deconvoluted using Gaussian function with "quasi-identical" wavenumber positions (variation of the peaks position maintained below $15 \mathrm{~cm}^{-1}$ ) and constant width. To take into account the low frequency region contribution on the high frequency region, a unique vibration has been implemented in order to simulate the tail effect. The vibrational band wavenumber and assignments used for the deconvolution from both series are respectively listed in Table 3. Based on the work of Kamitsos et al. [39] on Germanium - Rubidium glass systems, the bands located around $\sim 755 \mathrm{~cm}^{-1}$ (\# 2) and $\sim 825 \mathrm{~cm}^{-1}$ (\# 4) can be respectively attributed to $v(\mathrm{Ge}-\mathrm{O})$ stretching vibration respectively in $Q_{2}\left(\mathrm{Ge}_{2} \mathrm{O}_{2}\right)$ or $Q_{3}$ units $\left(\mathrm{Ge} \varnothing_{3} \mathrm{O}\right)^{-}$ respectively. Following the work from Skopak et al. [36] the Raman and infrared bands positioned around $785 \mathrm{~cm}^{-1}$ (\# 3) and $~ 890 \mathrm{~cm}^{-1}$ (\# 5) can be ascribed to localized stretching vibrational modes involved in $\mathrm{T}^{[4]}$ $-\mathrm{O}-\mathrm{T}^{[4]}$ bridges. The combined Raman and infrared activity indicates the presence of negatively charged $\mathrm{Ge}^{[4]}-\mathrm{O}^{-}-\mathrm{Ga}^{[4]}$ bonds with alternatively interconnected gallium and germanium tetrahedra where the charge compensation of those links is either achieved by lanthanum or barium cations. The remaining vibrational modes located at $\sim 690 \mathrm{~cm}^{-1}$ (\# 1) could be assigned to localized stretching frequency $v(\mathrm{Ga}-\mathrm{O})$ in $Q_{3}\left(\mathrm{GaO}_{4}\right)^{2-}$ units being charge compensated with either barium or lanthanum as proposed by Yoshimoto et al. [40]. In relative intensity, the intensities of the bands located around $\sim 755 \mathrm{~cm}^{-1}$ (\# 2) and $\sim 825 \mathrm{~cm}^{-1}$ (\# 4) increases significantly while raising the $\mathrm{BaO}$ content. Even if Kamitsos et al. [39] attributed those vibrations to $Q_{2}$ and $Q_{3}$ units, one has to be prudent here on a precise assignment in particular on the band at $755 \mathrm{~cm}^{-1}$. Nevertheless, it remains reasonable to claim that the evolution of those vibrations correspond to the presence on non-bridging oxygen on germanium moieties. Further structural characterizations such as ${ }^{71} \mathrm{Ga}$ NMR need to be performed for a more detailed assignment. 

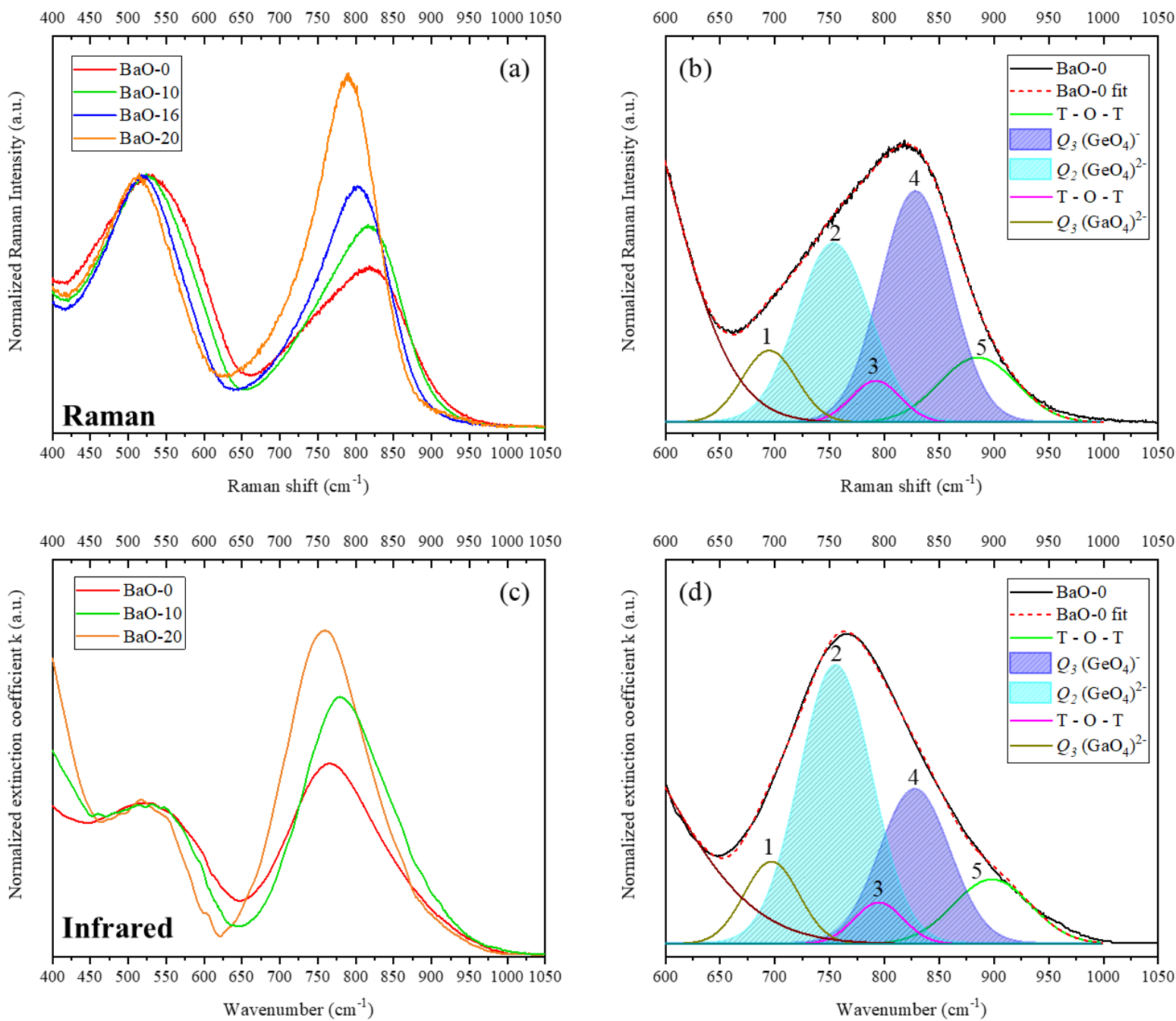

Figure 5: (a) Unpolarized Raman spectra for the $\mathrm{BaO}$ series and (b) Raman deconvoluted spectra for the glass sample BaO-0 (c) Fourier transformed infrared spectra for the $\mathrm{BaO}$ series. (c) Fourier transformed infrared spectra deconvoluted for the glass sample $\mathrm{BaO}-0$ for the high wavenumber frequency section fitting the tail of the low frequency region are fitted with a single Gaussian.

\begin{tabular}{cccc}
\hline $\begin{array}{c}\text { Band } \\
\text { number }\end{array}$ & $\begin{array}{c}\text { Wavenumber } \\
\left(\mathrm{cm}^{-1}\right)\end{array}$ & Assignements & References \\
\hline 1 & $\sim 690$ & $v(\mathrm{Ga}-\mathrm{O})$ stretching involved in $Q_{3}\left(\mathrm{GaO}_{4}\right)^{-}$units being charge compensated & {$[33]$} \\
\hline 2 & $\sim 755$ & $v(\mathrm{Ge}-\mathrm{O})$ stretching involved in $Q_{2}$ units $\left(\mathrm{Ge} \varnothing_{2} \mathrm{O}_{2}\right)^{2-}$ & {$[39]$} \\
\hline 3 & $\sim 785$ & $v\left(\mathrm{~T}^{[4]}-\mathrm{O}-\mathrm{T}^{[4]}\right)$ including mainly $\mathrm{Ga}-\mathrm{O}^{-}-\mathrm{Ge}$ alternance & {$[34]$} \\
\hline 4 & $\sim 825$ & $v(\mathrm{Ge}-\mathrm{O})$ stretching involved in $Q_{3}$ units $\left(\mathrm{Ge} \varnothing_{3} \mathrm{O}\right)^{-}$ & {$[39]$} \\
\hline 5 & $\sim 890$ & $v\left(\mathrm{~T}^{[4]}-\mathrm{O}-\mathrm{T}^{[4]}\right)$ including mainly $\mathrm{Ga}-\mathrm{O}^{-}-\mathrm{Ge}$ alternance & {$[34]$} \\
\hline
\end{tabular}

Table 3: Main Raman and infrared vibrational modes representing the high frequency region in the investigated $\mathrm{BaO}$ glass series based on the literature 
The Raman and infrared spectra of the $\mathrm{GeO}_{2}$ glass series with $\mathrm{LaO}_{3 / 2} / \mathrm{GaO}_{3 / 2}$ constant ratio, are presented in Figure 6. In the low frequency region, the Raman peak shifts from $\sim 510 \mathrm{~cm}^{-1}$ up to $530 \mathrm{~cm}^{-1}$ while the Infrared peak shifts from $\sim 554 \mathrm{~cm}^{-1}$ down to $\sim 502 \mathrm{~cm}^{-1}$. Those shifts are assigned to the vibrational spectral signatures of a change of network skeleton from $\mathrm{Ge}-\mathrm{O}-\mathrm{Ge}$ combined vibrational modes for the benefit $\mathrm{Ga}-\mathrm{O}^{-}-\mathrm{Ge}$ bridges while adding gallium oxide. In the high frequency region, the band located above $800 \mathrm{~cm}^{-1}$ previously ascribed to $\mathrm{T}-\mathrm{O}-\mathrm{T}$ bridges alternating germanium and gallium tetrahedral and $Q_{3}$ germanate units is no more present in the pure gallate glass matrix in Raman and Infrared spectroscopy. This effect is clearly visible in the infrared spectra showing that the asymmetric stretching of germanium units with non-bridging oxygens vibrating above $800 \mathrm{~cm}^{-1}$ decreases in magnitude when the germanium oxide content decreases and shifts from $825 \mathrm{~cm}^{-1}$ for Ge-68 to reach $760 \mathrm{~cm}^{-1}$ for the composition Ge-40. In the case of pure gallate sample (Ge- 0 ), the contribution around $\sim 760 \mathrm{~cm}^{-1}$ could be related to $v(\mathrm{Ga}-\mathrm{O}-\mathrm{Ga})$ stretching mode [41], [42]. In this gallate glass composition, new contributions are observed around $\sim 630 \mathrm{~cm}^{-1}$ and $\sim 690 \mathrm{~cm}^{-1}$ in the Raman and IR spectra respectively which increases upon the addition of gallium oxide content. Yoshimoto et al. in binary lanthanum-gallate glasses have assigned the Raman band at around $630 \mathrm{~cm}^{-1}$ to $v\left(\mathrm{Ga}^{[4,5,6]}-\mathrm{O}\right)$ stretching vibration arising from either gallium polyhedra $\left(\mathrm{GaO}_{\mathrm{x}}\right)_{4 \leq \mathrm{x} \leq 6}$ with possibly non-bridging oxygens (NBOs) or gallate tri-clusters $\left(\mathrm{Ga}^{[4]}-\mathrm{O}^{[3]}\right)[41]$. 

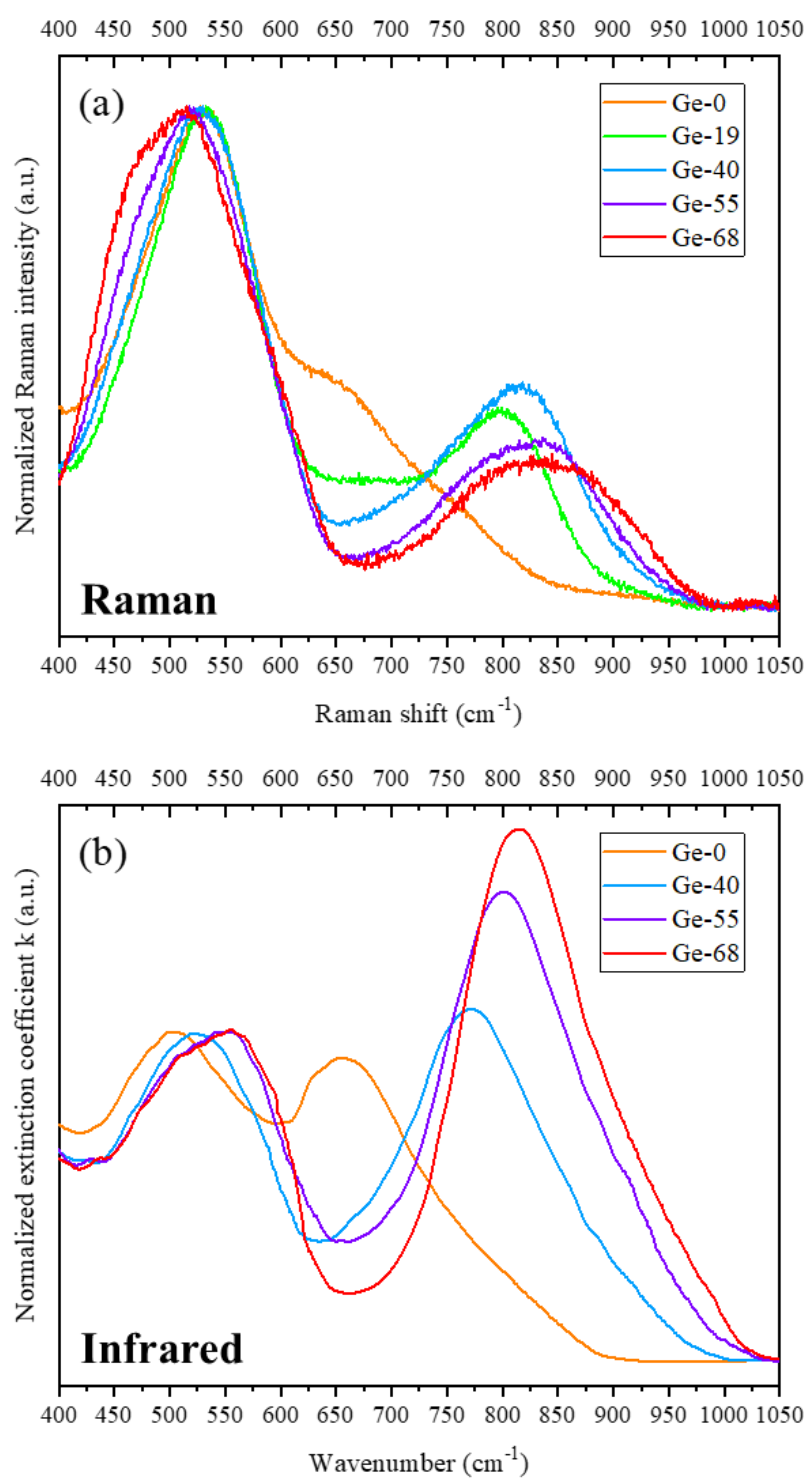

Figure 6: (a) Unpolarized Raman spectra and (b) Fourier Transformed InfraRed spectra for the $\mathrm{GeO}_{2}$ glass series

\section{Discussion.}

The key points for understanding the germano - gallate glass structures and properties rely on the investigation of the charge compensation mechanism of charged gallate units, in particular the $\left[\mathrm{GaO}_{4}\right]^{-}$units and the formation of either by $Q_{i=1,2,3,4}$ germanate or gallate units. The glass structure can be compared to the aluminosilicate glass structures. Indeed, gallium cations are expected to act as aluminum in $\left(\mathrm{M}_{2} \mathrm{O}\right.$ or $\left.\mathrm{MO}\right)-$ $\mathrm{Al}_{2} \mathrm{O}_{3}-\mathrm{SiO}_{2}$-based vitreous systems [21], [38]. In other words, gallium oxide, as alumina oxide, generally enters into the network in four-fold tetrahedral corner shared entities. Once inserted, $\mathrm{Ga}^{3+}\left(\mathrm{Al}^{3+}\right)$ substitute $\mathrm{Ge}^{4+}\left(\mathrm{Si}^{4+}\right)$ which produces an additional localized negative charge on the $\mathrm{Ga}^{[4]}\left(\mathrm{Al}^{[4]}\right)-\mathrm{O}^{-}-\mathrm{Ge}^{[4]}\left(\mathrm{Si}^{[4]}\right)$ bridges. Those links are then charge-balanced by $\mathrm{M}^{\mathrm{z}}$ cations, acting mostly as charge compensators. At this point, both cases could be considered depending on the polymerization and the charge ratios respectively defined as $\mathrm{R}=\left[\mathrm{GaO}_{3 / 2}\right] /\left[\mathrm{GeO}_{2}\right]$ and $\mathrm{Q}=\mathrm{z}^{+}[\mathrm{M}] /\left[\mathrm{GaO}_{3 / 2}\right]$. When $\mathrm{R}>1$ and $\mathrm{Q} \leq 1$, gallate units tend to change 
their coordination number, forming a fraction of higher coordinated gallate units such as $\mathrm{GaO}_{5}$ or $\mathrm{GaO}_{6}$ [36]. Whereas $\mathrm{R}$ and $\mathrm{Q}$ fulfill the conditions $\mathrm{R} \leq 1$ and $\mathrm{Q} \geq 1$, the remaining $\mathrm{M}^{\mathrm{z}}$ positive cations depolymerizes the network, acting as glass modifiers [36]. Those cations create mainly localized non-bridging oxygens (labelled "NBOs") on germanate tetrahedra with localized stretching at $755 \mathrm{~cm}^{-1}$ and $825 \mathrm{~cm}^{-1}$ units. The investigated barium series $(\mathrm{BaO})$ fully satisfy the conditions $\mathrm{R} \leq 1$ and $\mathrm{Q} \geq 1$. In agreement with both Infrared and Raman vibrational activity assigned to $\mathrm{T}^{[4]}-\mathrm{O}-\mathrm{T}^{[4]}$ stretching modes, the glass skeleton is made of a threedimensional corner shared tetrahedral formed with $\mathrm{Ga}^{[4]}-\mathrm{O}^{-}-\mathrm{Ge}^{[4]}$ bridges. The gallium lies in tetrahedral sites and its charge compensation is mainly satisfied by lanthanum $\mathrm{La}^{3+}$ or barium $\mathrm{Ba}^{2+}$ cations. For $\mathrm{Q} \geq 1$, the excess of positive charges produces mainly non-bridging oxygens on germanium sites $Q_{3}\left(\mathrm{Ge} \varnothing_{3} \mathrm{O}\right)^{-}$. Indeed, the Raman vibration localized at to $755 \mathrm{~cm}^{-1}$ corresponding to NBOs on germanate entities becomes dominant above 16 cat mol \% of $\mathrm{BaO}$.

Regarding the structure - properties relationships, the slight decrease of the density upon the barium oxide insertion up to 16 cat mol \% follows the glass structure evolution with the progressive appearance of germanium site with non-bridging oxygen which tend to depolymerize the glass skeleton formed of corner shared tetrahedra. For BaO-20 glass, for which the NBOs vibration becomes predominant, a significant density drop can be observed. This evolution of the density is accompanied by a continuous decrease of the glass transition temperature which tend to stabilize for $\mathrm{BaO}-16$ and $\mathrm{BaO}-20$. This evolution is again in accordance with the progressive depolymerization of the glass network.

Regarding the $\mathrm{GeO}_{2}$ glass series, the composition range investigated covers two different glass networks: $(i)$ germanate-based glass network from Ge-68 to Ge-40 and (ii) gallate-based network from Ge-40 up to Ge-0. In Figure. 2, two different evolutions for the glass transition temperatures and the densities are clearly observed depending on the main network former. Regarding the germanate part (Ge-68 to Ge-40), the glass network polymerizes with the progressive increase of gallium oxide, leading to the formation of $\mathrm{Ge}^{-} \mathrm{O}^{-}-\mathrm{Ga}$ bridges in which the gallium tetrahedra are charged-balanced by lanthanum and barium. This structural evolution is in accordance with the linear increase of $T_{g}$ and densities. Above Ge-40, the slope of $T_{g}$ and density versus the amount of $\mathrm{GaO}_{3 / 2}$ evolves slowly. This evolution corresponds to the disappearance of the germanium sites with non-bridging oxygens and the formation of a gallate glass network. Those physical variations may rely on the formation of new polyhedral units such as $\left(\mathrm{GaO}_{\mathrm{x}}\right)_{4 \leq \mathrm{x} \leq 6}$ units with possible non-bridging oxygens or oxygen tri-clusters $\left(\mathrm{Ga}-\mathrm{O}^{[3]}\right)$. Nonetheless, such hypothesis needs to be confirmed by ${ }^{17} \mathrm{O}$ NMR for instance.

\section{Conclusion}

The existence domains of glass in the multicomponent $\mathrm{GaO}_{3 / 2}-\mathrm{GeO}_{2}-\mathrm{LaO}_{3 / 2}-\mathrm{BaO}$ pseudo-ternary diagrams while varying the amount of Barium oxide from 0 cat mol $\%$ up to 20 cat mol \% were determined using aerodynamic levitation coupled to laser heating as a synthesis tool. The introduction of barium oxide allows the glass-forming region to be widened. Gallium and germanium ions occupy tetrahedral sites and form a three dimensional network with T-O-T bridges $(\mathrm{T}=\mathrm{Ge}, \mathrm{Ga})$. In germano-gallate glass network, the barium and lanthanum ions play the role of charge compensator of oxygen in Ge-O-Ga bridges. The excess of positive charge is mainly balanced by the formation of $Q_{3}\left(\mathrm{Ge}_{3} \mathrm{O}\right)^{-}$germanate units. The decrease of the glass 
transition temperatures is associated with the progressive increase of those $\mathrm{Q}_{3}$ units on the germanium. The extended infrared transmission of gallate is proposed to be related with the existence of gallium oxygenated sites with possibly non-bridging oxygens or the formation of oxygen tri-clusters vibrating at lower frequency than that the of germanium germano-gallate based structural units.

\section{Acknowledgements}

This research was supported by Agence Nationale de la Recherche (ANR) (ANR-18-CE08-0004-02) and the New Aquitaine Region. This project has received funding from the European Union's Horizon 2020 research and innovation program under the Marie Skłodowska-Curie grant agreement No 823941 (FUNGLASS), as well as grants of the Agence Nationale de la Recherche (ANR) with the program "Investissement d'avenir" number ANR-10-IDEX-03-02. M. Nalin acknowledge the São Paulo Research Foundation, FAPESP (grant numbers 2013/07793-6 and 2019/01223-0). The authors acknowledge the platform SIV for vibrational spectroscopy characterizations.

\section{$\underline{\text { References }}$}

[1] M. Sieger et B. Mizaikoff, "Toward On-Chip Mid-Infrared Sensors", Anal. Chem., vol. 88, n 11, p. 5562-5573, juin 2016, doi: 10.1021/acs.analchem.5b04143.

[2] N. A. Diakides et J. D. Bronzino, "Medical Infrared Imaging". CRC Press, 2007.

[3] W. H. Dumbaugh et J. C. Lapp, "Heavy-Metal Oxide Glasses" , J American Ceramic Society, vol. 75, no 9, p. 2315-2326, sept. 1992, doi: 10.1111/j.1151-2916.1992.tb05581.x.

[4] W. H. Dumbaugh, "Oxide Glasses With Superior Infrared Transmission" , in Advances in Optical Materials, déc. 1984, vol. 0505, p. 97-101, doi: 10.1117/12.964633.

[5] S. J. L. Ribeiro, J. Dexpert-Ghys, B. Piriou, et V. R. Mastelaro, "Structural studies in lead germanate glasses: EXAFS and vibrational spectroscopy" , Journal of Non-Crystalline Solids, vol. 159, no 3, p. 213-221, janv. 1993, doi: 10.1016/0022-3093(93)90225-M.

[6] Fumiaki Miyaji, Sumio Sakka, "Structure of $\mathrm{PbO}-\mathrm{Bi}_{2} \mathrm{O}_{3}-\mathrm{Ga}_{2} \mathrm{O}_{3}$ glasses,", Journal of Non-Crystalline Solids, Volume 134, Issues 1-2, 1991, Pages 77-85,ISSN 0022-3093,https://doi.org/10.1016/00223093(91)90013-V.

[7] B. G. Aitken and N. F. Borelli, “Thallium gallate glasses,” US 5,168,079, 1992.

[8] N. F. Borrelli, H. Dumbaugh, D. W. Hall, M. A. Newhouse, M. L. Powley, et D. L. Weidman, « galliobismuthate gallate glasses », US 5,093,287

[9] J. C. Lapp and M. L. Powley, "Alkali bismuth gallate glasses,” US 5,114,884, 1992.

[10] Fumiaki Miyaji, Kiyoharu Tadanaga, Toshinobu Yoko, Sumio Sakka, "Coordination of $\mathrm{Ga}^{3+}$ ions in $\mathrm{PbO}-\mathrm{Ga}_{2} \mathrm{O}_{3}$ glasses as determined by $71 \mathrm{Ga}$ NMR", Journal of Non-Crystalline Solids, Volume 139, 1992, Pages 268-270, ISSN 0022-3093, https://doi.org/10.1016/S0022-3093(05)80834-8.

[11] John M. Jewell, Jacqueline A. Ruller, "A structural model for $\mathrm{PbO}-\mathrm{Ga}_{2} \mathrm{O}_{3}-\mathrm{SiO}_{2}$ glasses", Journal of Non-Crystalline Solids, Volume 152, Issues 2-3, 1993, Pages 179-187, ISSN 0022-3093, https://doi.org/10.1016/0022-3093(93)90249-W.

[12] J. Yumoto, S. G. Lee, B. Kippelen, N. Peyghambarian, B. G. Aitken, et N. F. Borrelli, "Enhancement of optical nonlinearity of heavy-metal oxide glasses by replacing lead and bismuth with thallium", Appl. Phys. Lett., vol. 63, no 19, p. 2630-2632, nov. 1993, doi: 10.1063/1.110403.

[13] H. Lin, L. W. Dechent, D. E. Day, et J. O. Stoffer, "IR transmission and corrosion of lead-bismuth gallate glasses" , Journal of Non-Crystalline Solids, vol. 171, n 3, p. 299-303, août 1994, doi: 10.1016/0022-3093(94)90199-6.

[14] J. A. Ruller et J. M. Jewell, "Raman and infrared spectra of lead gallosilicate glasses", Journal of NonCrystalline Solids, vol. 175, no 1, p. 91-97, sept. 1994, doi: 10.1016/0022-3093(94)90319-0.

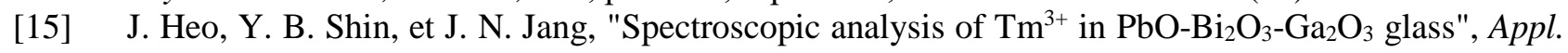
Opt., vol. 34, nº 21, p. 4284, juill. 1995, doi: 10.1364/AO.34.004284.

[16] A. C. Hannon, J. M. Parker, et B. Vessal, "The effect of composition in lead gallate glasses: a structural study", Journal of Non-Crystalline Solids, vol. 196, p. 187-192, mars 1996, doi: 10.1016/00223093(95)00584-6. 
[17] A. A. Kharlamov, R. M. Almeida, et J. Heo, "Vibrational spectra and structure of heavy metal oxide glasses", Journal of Non-Crystalline Solids, vol. 202, nº 3, p. 233-240, juill. 1996, doi: 10.1016/00223093(96)00192-5.

[18] Y. G. Choi, J. Heo, et V. A. Chernov, "Ga K-edge EXAFS analysis on the coordination of gallium in $\mathrm{PbO}-\mathrm{Ga}_{2} \mathrm{O}_{3}$ glasses", Journal of Non-Crystalline Solids, vol. 221, nº 2-3, p. 199-207, déc. 1997, doi: 10.1016/S0022-3093(97)00418-3.

[19] D. Lezal, J. Pedlikova, P. Kostka, J. Bludska, M. Poulain, et J. Zavadil, "Heavy metal oxide glasses: preparation and physical properties", Journal of Non-Crystalline Solids, vol. 284, no 1-3, p. 288-295, mai 2001, doi: 10.1016/S0022-3093(01)00425-2.

[20] S. Simon et V. Simon, "Thermal characterisation of gallium-bismuthate oxide glasses", Materials Letters, vol. 58, no 29, p. 3778-3781, nov. 2004, doi: 10.1016/j.matlet.2004.07.042.

[21] P. L. Higby et I. D. Aggarwal, "Properties of barium gallium germanate glasses", Journal of NonCrystalline Solids, vol. 163, n 3, p. 303-308, déc. 1993, doi: 10.1016/0022-3093(93)91308-P.

[22] S. S. Bayya, B. B. Harbison, J. S. Sanghera, et I. D. Aggarwal, "BaO- $\mathrm{Ga}_{2} \mathrm{O}_{3}-\mathrm{GeO}_{2}$ glasses with enhanced properties", Journal of Non-Crystalline Solids, vol. 212, n 2, p. 198-207, juin 1997, doi: 10.1016/S0022-3093(96)00658-8.

[23] S. S. Bayya, G. D. Chin, J. S. Sanghera, et I. D. Aggarwal, "Germanate glass as a window for high energy laser systems", Optics Express, vol. 14, n 24, p. 11687, 2006, doi: 10.1364/OE.14.011687.

[24] S. S. Bayya, G. D. Chin, G. Villalobos, J. S. Sanghera, et I. D. Aggarwal, "VIS-IR transmitting windows", Orlando, Florida, USA, mai 2005, p. 262, doi: 10.1117/12.603753.

[25] I. S. S.- Bayya, J. S. Sanghera, et I. D. Aggaral, "Optical transmission of BGG glass material", WO 2005069761 A2, 2004.

[26] T. Skopak, F. Calzavara, Y. Ledemi, F. Célarié, M. Allix, E. Véron, M. Dussauze, T. Cardinal, E. Fargin, Y. Messaddeq, "Properties, structure and crystallization study of germano-gallate glasses in the Ga2O3-GeO2-BaO-K2O system", Journal of Non-Crystalline Solids, vol. 514, p. 98-107, juin 2019, doi: 10.1016/j.jnoncrysol.2019.02.028.

[27] T. Guérineau, C. Strutynski, T. Skopak, S. Morency, A. Hanafi, F. Calzavara, Y. Ledemi, S. Danto, T. Cardinal, Y. Messaddeq, E Fargin, "Extended germano-gallate fiber drawing domain: from germanates to gallates optical fibers", Opt. Mater. Express, vol. 9, nº 6, p. 2437, juin 2019, doi: 10.1364/OME.9.002437.

[28] S. Szu, C. Shu, et L.-G. Hwa, « Structure and properties of lanthanum galliogermanate glasses », Journal of Non-Crystalline Solids, vol. 240, $\mathrm{n}^{\circ}$ 1-3, p. 22-28, oct. 1998, doi: 10.1016/S00223093(98)00710-8.

[29] L.-G. Hwa, J.-G. Shiau, et S.-P. Szu, "Polarized Raman scattering in lanthanum gallogermanate glasses", Journal of Non-Crystalline Solids, vol. 249, nº 1, p. 55-61, juill. 1999, doi: 10.1016/S00223093(99)00300-2.

[30] L.-G. Hwa, Y.-R. Chang, et S.-P. Szu, "Optical and physical properties of lanthanum gallogermanate glasses", Journal of Non-Crystalline Solids, vol. 231, n 3, p. 222-226, août 1998, doi: 10.1016/S00223093(98)00455-4.

[31] Hwa, L.G., Chao, W.C. \& Szu, S.P. "Temperature dependence of elastic moduli of lanthanum gallogermanate glasses", Journal of Materials Science 37, 3423-3427 (2002). https://doi.org/10.1023/A:1016550720293

[32] Hwa, LG., Lay, HY. \& Szu, SP. "Elastic properties of lanthanum gallogermanate glasses", Journal of Materials Science 34, 5999-6002 (1999). https://doi.org/10.1023/A:1004736913276

[33] J. M. Jewell, P. L. Higby, et I. D. Aggarwal, "Properties of BaO-R2O3- Ga2O3-GeO2 (R = Y, Al, La, and Gd) Glasses", J American Ceramic Society, vol. 77, $\mathrm{n}^{\circ}$ 3, p. 697-700, mars 1994, doi: 10.1111/j.1151-2916.1994.tb05351.x.

[34] L. G. Hwa, Y. R. Chang, et W. C. Chao, "Infrared spectra of lanthanum gallogermanate glasses", Materials Chemistry and Physics, vol. 85, $\mathrm{n}^{\mathrm{o}}$ 1, p. 158-162, mai 2004, doi: 10.1016/j.matchemphys.2003.12.021.

[35] Luo, Y.-R. (2007). "Comprehensive Handbook of Chemical Bond Energies" (1st ed.), CRC Press. https://doi.org/10.1201/9781420007282

[36] T. Skopak et al., "Structure and Properties of Gallium-Rich Sodium Germano-Gallate Glasses", The Journal of Physical Chemistry $C$, vol. 123, $\mathrm{n}^{\mathrm{o}}$ 2, p. 1370-1378, janv. 2019, doi: 10.1021/acs.jpcc.8b08632. 
[37] G. S. Henderson, L. G. Soltay, et H. M. Wang, "Q speciation in alkali germanate glasses", Journal of Non-Crystalline Solids, vol. 356, $\mathrm{n}^{\circ} 44-49, \quad$ p. 2480-2485, oct. 2010, doi: 10.1016/j.jnoncrysol.2010.03.023.

[38] D. M. McKeown et C. I. Merzbacher, "Raman spectroscopic studies of $\mathrm{BaO}-\mathrm{Ga}_{2} \mathrm{O}_{3}-\mathrm{GeO}_{2}$ glasses", Journal of Non-Crystalline Solids, vol. 183, $\mathrm{n}^{\circ}$ 1-2, p. 61-72, avr. 1995, doi: 10.1016/00223093(94)00648-2.

[39] E. I. Kamitsos, Y. D. Yiannopoulos, M. A. Karakassides, G. D. Chryssikos, et H. Jain, "Raman and Infrared Structural Investigation of xRb2O·(1-x)GeO2 Glasses", J. Phys. Chem., vol. 100, no 28, p. 11755-11765, janv. 1996, doi: 10.1021/jp960434+.

[40] K. Yoshimoto, A. Masuno, M. Ueda, H. Inoue, H. Yamamoto, et T. Kawashima, "Low phonon energies and wideband optical windows of $\mathrm{La}_{2} \mathrm{O}_{3}-\mathrm{Ga}_{2} \mathrm{O}_{3}$ glasses prepared using an aerodynamic levitation technique", Scientific Reports, vol. 7, n 1, déc. 2017, doi: 10.1038/srep45600.

[41] K. Yoshimoto et al., "Principal Vibration Modes of the $\mathrm{La}_{2} \mathrm{O}_{3}-\mathrm{Ga}_{2} \mathrm{O}_{3}$ Binary Glass Originated from Diverse Coordination Environments of Oxygen Atoms", J. Phys. Chem. B, vol. 124, no 24, p. 5056-5066, juin 2020, doi: 10.1021/acs.jpcb.0c02147.

[42] J. Hanuza et M. Andruszkiewicz, "Phonon properties and normal coordinate analysis of galliumoxygen core in BaLaGa3O7 crystal", Spectrochimica Acta Part A: Molecular and Biomolecular

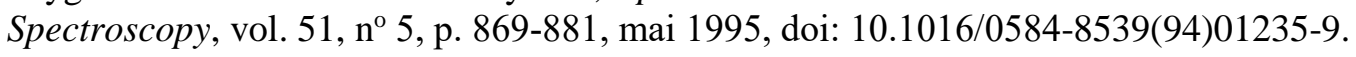

